\title{
THE NATURAL HISTORY OF THE ANTERIOR KNEE INSTABILITY BY STRESS RADIOGRAPHY
}

\author{
Márcia Uchôa de Rezende ${ }^{1}$, Arnaldo José Hernandez ${ }^{1}$, Gilberto Luis Camanho
}

\begin{abstract}
Objective: To analyze the anteroposterior displacement of the knee by means of stress radiography in individuals with unilateral anterior knee instability and relate to time of instability. Methods: Sixty individuals with intact knees (control group) and 125 patients with unilateral anterior instability (Al group) agreed to participate in the study. Gender, age, weight, height, age at injury, time between injury and testing, and surgical findings are studied. Both groups are submitted to anterior and posterior stress radiographies of both knees. Anterior (ADD) and posterior displacement difference (PDD) were calculated between sides. Results: In the control group ADD and PDD are in average, zero, whereas in the Al group ADD averaged
\end{abstract}

9.8mm and PDD, $1.92 \mathrm{~mm}$. Gender, age, weight, height, age at trauma and presence of menisci's lesions do not intervene in the values of ADD and PDD. Meniscal injuries increase with time. ADD and PDD do not relate with the presence or absence of associated menisci's lesions. The ADD and the PDD are related to each other and increase with time. Conclusion: There is a permanent anterior subluxation of the injured knee that is related to the amount of anterior displacement that increases with time. Level of Evidence III, Study Types Case-control study.

Keywords: Knee injuries/radiography. Knee joint. Joint instability. Menisci, tibial.

Citation: Rezende MU, Hernandez AJ, Camanho GL. The natural history of the anterior knee instability by stress radiography. Acta Ortop Bras. [online]. 2014;22(4):183-7. Available from URL: http://www.scielo.br/aob.

\section{INTRODUCTION}

The anterior knee instability is the result of the anterior cruciate ligament $(\mathrm{ACL})$ rupture, whose primary function is to limit the anterior translation of the tibia in relation to the femur. ${ }^{1}$ The $\mathrm{ACL}$ injury is relatively frequent in sports practice and the instability caused by its lesion precludes the sports practice in the same skill level. ${ }^{2}$

Scientifically, it is an advantage to be able to measure the joint's instability in physical units. ${ }^{3,4}$ The result of a given treatment can be quantified by the mensuration of the stability before and after this treatment. ${ }^{4}$

The radiological demonstration of the sagittal instability was described in 1944 by Böhler. ${ }^{5}$ The actual measurement of the sagittal knee instability by means of radiographies before and after submitting the joint to known standardized traction, in different directions was only demonstrated in 1971 by Kennedy and Fowler. ${ }^{6}$

The stress radiography is the simplest and most reliable method for the evaluation of the knee laxity, specially at $20^{\circ}$ of knee flexion. ${ }^{3,4,7-11}$ It indicates which ligaments are injured. ${ }^{4,12}$

Several stress radiographic methods for sagittal knee instability have been described in the literature: passive, active, at full extension, at $20^{\circ}$ and $90^{\circ}$ of knee flexion. ${ }^{3-10,13}$

The purposes of this study are: to use a standardized passive sagittal stressradiographic method of the knee, for comparing the behavior of a population without affections of both knees, with unilateral ACL deficient patients, and determine if there are variables, such as body composition, age, meniscal injuries and time between trauma and stress radiography, that intervene in the magnitude of the anterior and posterior displacement of the tibia in intact and ACL-deficient knees.

\section{MATERIALS AND METHODS}

This study was approved by the Ethics Committee of Hospital das Clínicas, Universidade de São Paulo number 224/93. All participants signed informed consent forms.

Thirty men and 30 women (120 knees) without history of any affection to the lower limbs such as strains, fractures, surgeries, knee angular deformities; inequality of lower limbs, neurological affections; collagen diseases or pregnancy composed the control group.

The mean age was 28.2 years old (16 to 44$)$. The average weight

All the authors declare that there is no potential conflict of interest referring to this article.

1. Departamento de Ortopedia e Traumatologia da Faculdade de Medicina da Universidade de São Paulo, São Paulo, SP, Brazil.

Study conducted at the LIM 41 - Laboratório de Investigação Médica do Sistema Músculo-Esquelético do Departamento de Ortopedia e Traumatologia da Faculdade de Medicina da Universidade de São Paulo, Brazil.

Correspondence: Departamento de Ortopedia e Traumatologia, Faculdade de Medicina da Universidade de São Paulo. Rua Dr. Ovídio Pires de Campos, 333. Cerqueira Cesar - São Paulo, SP, Brazil. murezende@uol.com.br 
was $62 \mathrm{~kg}$ (42 to 92) and height of 1.66 meters (1.40 to 1.98). This group matched the anterior instability group (Al group) in age (Student $T$ test $p=0.33$ ).

The Al group was composed of 125 individuals with unilateral anterior knee instability. All patients had a history of ACL injury, followed by symptoms and physical examinations of anterior knee instability for a period no lesser than 4 months.

Twelve women and 113 men fulfilled all the items described above. The mean age was 29.5 years old (16 to 65$)$. The average weight was $72.2 \mathrm{~kg}$ (51 to 110). The average height was $1.73 \mathrm{~m}$ (1.50 to 2.05) and time between injury and stressradiography of these patients varied from 0.3 years to 32 years (average 3.94). Weight and height matched the male population of the control group.

Of the 125 patients, 79 were submitted to surgical treatment of the ACL and associated lesions. Thirty-five had isolated ACL rupture (subgroup $\mathrm{ACL}$ ), and 44 had associated medial and/ or lateral meniscus injury (subgroup ACLMM). The patients not submitted to surgical treatment were classified as subgroup not operated (N-OPER).

Weight and height of the control group (62.2 $\mathrm{kg}$ and $1.66 \mathrm{~m})$ was significantly less than the Al group $(72.2 \mathrm{~kg}$ and $1.73 \mathrm{~m})$ and its subgroups ACL (71.1 kg and 1.73m), ACLMM (72.43kg and $1.73 \mathrm{~m})$ and N-OPER (72.9kg and $1.73 \mathrm{~m})$ (Kruskal-Wallis, $p=0$ ). Time between injury and stressradiographic examination varied from 0.3 in all subgroups to 10 years in the ACL group (average 2.11 ); to 32 years in the ACLMM (average 5.72) and 23 years in the N-OPER group (average 3.56), $p=0.23$, Kruskal-Wallis. The N-OPER group was older (27.5years) at trauma then the patients from the subgroups ACL (24.5years) (Dunn $p=0.05$ ) and ACLMM (24.33) (Dunn $\mathrm{p}=0.03$ ).

\section{Stressradiography}

All the subjects from the control group and all the patients from the Al group were submitted to lateral stressradiographs of both knees at $20^{\circ}$ of flexion. The applied force was $10 \%$ of body weight in the anterior and posterior direction. ${ }^{9}$ These radiographic examinations were called stressradiographies or radiographic Lachman.

The anterior stress examination is made with the device placed under the proximal leg. The lock is positioned over the ankle. The load is applied over the patient's distal thigh, $5 \mathrm{~cm}$ above the superior pole of the patella. (Figure 1A)

The posterior stress examination is made with the body of the apparatus placed under the distal thigh. The heel rests over a rigid support. The load applied in the anterior stress is now applied over the proximal tibia, stressing it posterior. (Figure 1B)

\section{Measurement}

Initially, the posterior tibial cortex (PTC) and the posterior contour of each femoral and tibial condyle are identified. Next, the template is placed over the radiography with the referral longitudinal line over the PTC.

The distance between the parallel lines of the template that tangents the posterior limits of lateral femoral and tibial condyles are the measurement of the displacement of the lateral compartment. The distance between the two parallel lines that tangents the posterior contour of the medial fe- moral and tibial condyles is the measurement of the displacement of the medial compartment. The arithmetic average of these two displacements yields the displacement of this knee (maximum anterior (AD) or posterior displacement (PD)). (Figures 1C-F)

The measurement is positive if the tibial condyle is anterior to the respective femoral condyle and negative if the tibial condyle is posterior to the correspondent femoral condyle.

Once the measurements of AD and of PD are obtained for each knee of a given subject, the difference of displacement between sides under anterior (ADD) and posterior (PDD) stress must be calculated: right $(\mathrm{R})$ - left $(\mathrm{L})$ difference in the control group, and injured $(\mathrm{I})$ - uninjured $(\mathrm{U})$ difference in the Al group.

The measurement of the ADD, will be referred to as the anterior translation, and positive value of PDD, will be referred to as anterior subluxation. ${ }^{12}$
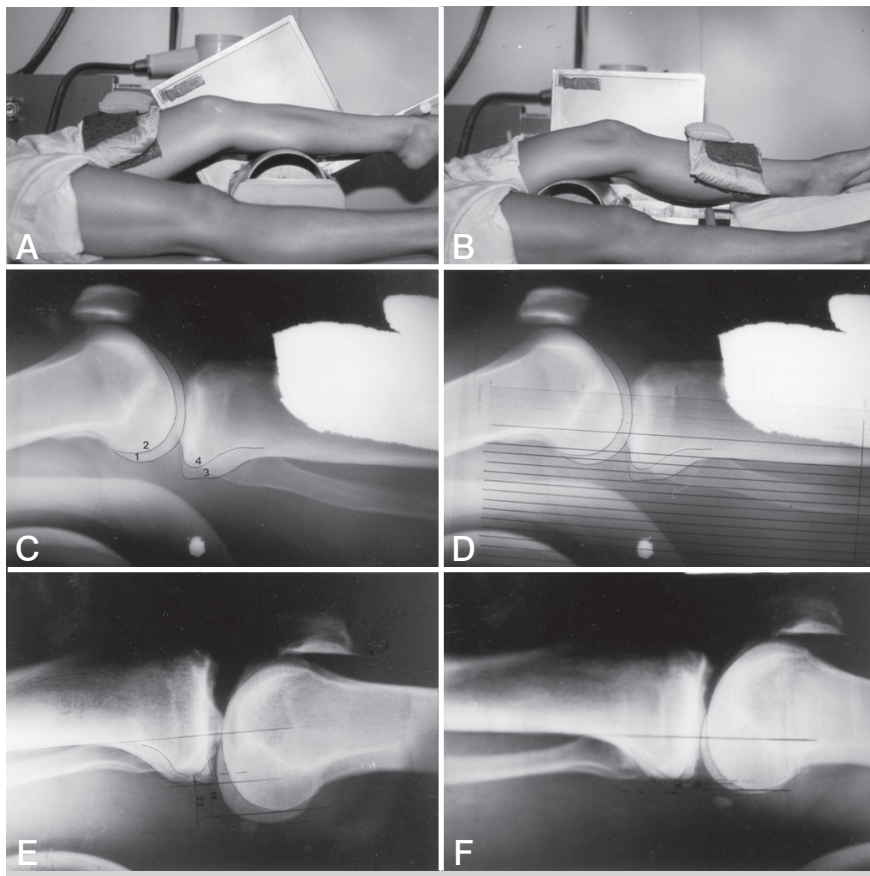

Figure 1. A) Anterior stress positioning (Anterior Radiographic Lachman Test) B) Posterior stress positioning (Posterior Radiographic Lachman Test); C) Stressradiography (posterior radiographic Lachman). Identification of the posterior contours of the femoral and tibial condyles. 1- medial femoral condyle; 2- lateral femoral condyle; 3- medial tibial condyle; 4- lateral tibial condyle; D) Stressradiography (posterior radiographic Lachman). Identification of the posterior contours of the femoral and tibial condyles and of the posterior tibial cortex (PTC). Transposition of the template for measuring the displacements of each compartment; E) Anterior radiographic Lachman of an anterior unstable knee; F) Positive posterior radiographic Lachman.

\section{Statistical Analysis}

Descriptive statistics were made for all ordinal sample values. Tests used: Student t for comparison of parametric samples; Mann-Whitney $U$ for the non-parametric samples; For related (paired) samples, the Wilcoxon; Kruskal-Wallis to compare more than two non-parametric samples, with discrimination by the comparison of means test modified by Dunn; The Pearson correlation and the linear regression test were applied in ordinal samples.

Significance level of $5 \%(\alpha=0.05)$ was adopted. 


\section{RESULTS}

The results of the difference of displacement between sides for the stress examinations in the anterior and posterior directions (ADD and $\mathrm{PDD}$ ) of the 60 control subjects are shown in Table 1. There is no gender difference and ADD and PDD were all close to zero. Age (years), weight (kg) and height (m) of control subjects did not correlate (Pearson's correlation test) with ADD and PDD values.

The results of the ADD and PDD of the 125 patients with anterior knee instability gender wise are analyzed in Table 2 showing no difference between sexes. In the Figure 2, the ADD histogram of the control and Al groups are shown. The ADD of the control and $\mathrm{Al}$ group with the respective values of the ACL, ACLMM and N-OPER groups are shown on Table 3. Figure 3 and Table 4 show the histogram and values of PDD in the control and Al group and subgroups.

We tested the correlation between ADD and/or PDD and age (years old), weight $(\mathrm{kg})$, height $(\mathrm{m})$, age at trauma, in years, and time between injury and stress radiography (TIME), We found a significant correlation between ADD and time between injury and stress radiography (Pearson's correlation coefficient of $0.2164, p=0.01$ ). The equation would be: $A D D=9.3+0.22$. (TIME). PDD significantly correlated with ADD (Pearson's correlation coefficient of $0.2109, p=0.021$. PDD $=0.4+0.2$. (ADD). Table 5 shows the average values of ADD and PDD with the years between injury and stress radiography. One can see the increasing values of PDD through the years, despite lack of statistical significance.

Table 1. Descriptive statistics of the anterior (ADD) and posterior (PDD) displacement difference between right and left sides, in millimeters, of the control group, according to sex. Mann-Whitney $U$ test $(\alpha=0.05)$.

\begin{tabular}{c|c|c|c|c}
\hline & \multicolumn{2}{|c|}{ ADD } & \multicolumn{2}{c}{ PDD } \\
\hline & Male & Female & Male & Female \\
\hline Mean & 0.18 & 0.17 & -0.50 & -0.22 \\
\hline Standard deviation & 1.51 & 1.18 & 1.61 & 1.65 \\
\hline Standard error of mean & 0.27 & 0.22 & 0.29 & 0.21 \\
\hline Minimum & -2.5 & -2.5 & -3.0 & -3.0 \\
\hline Maximum & +2.5 & +3.0 & +3.0 & 3.0 \\
\hline Number & 30 & 30 & 30 & 60 \\
\hline Mann-Whitney U test & $\mathrm{U}=449$ & $\mathrm{p}=0.99$ & $\mathrm{U}=346$ & $\mathrm{p}=0.12$ \\
\hline
\end{tabular}

Table 2. Descriptive statistic of the anterior (ADD) and posterior (PDD) displacement difference, in millimeters, between the injured and uninjured sides of the patients from the Al group, genderwise. Mann-Whitney U test $(\alpha=0.05)$

\begin{tabular}{c|c|c|c|c}
\hline & \multicolumn{2}{|c|}{ ADD } & \multicolumn{2}{c}{ PDD } \\
\hline & Male & Female & Male & Female \\
\hline Mean & 9.80 & 10.17 & 1.87 & 2.33 \\
\hline Standard deviation & 3.89 & 3.77 & 2.98 & 3.21 \\
\hline Standard error of mean & 0.37 & 1.09 & 0.28 & 0.93 \\
\hline Minimum & 3.0 & 4.5 & -3.5 & -2.5 \\
\hline Maximum & 22.5 & 16.5 & 11.0 & 7.0 \\
\hline Number & 113 & 12 & 113 & 12 \\
\hline Mann-Whitney U test & $\mathrm{U}=642$ & $\mathrm{p}=0.76$ & $\mathrm{U}=630$ & $\mathrm{p}=0.69$ \\
\hline
\end{tabular}

Acta Ortop Bras. 2014;22(4):183-7

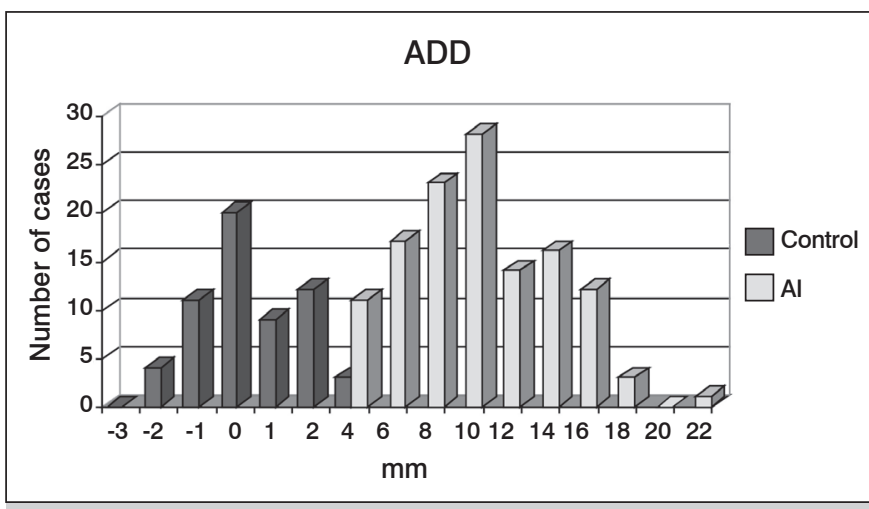

Figure 2. Histogram of the anterior displacement difference (ADD), in millimeters $(\mathrm{mm})$, of the control subjects (CONTROL) and of the patients with anterior knee instability (Al).

Table 3. Descriptive statistic of the anterior displacement difference between sides (ADD), in millimeters, of the Control and Al groups and of the subgroups ACL, ACLMM and N-OPER. Kruskal-Wallis comparison test and discrimination by the C.M test modified by Dunn $(\alpha=0.05)$.

\begin{tabular}{c|c|c|c|c|c}
\hline & ADD $(\mathrm{mm})$ & & & & \\
\hline & Control & Al & ACL & ACLMM & N-OPER \\
\hline Mean & 0.17 & 9.83 & 9.66 & 10.01 & 9.79 \\
\hline Standard deviation & 1.35 & 3.86 & 3.23 & 4.11 & 4.13 \\
\hline Standard error of mean & 0.17 & 0.35 & 0.55 & 0.62 & 0.61 \\
\hline Minimum & -2.5 & 3.0 & 3.5 & 3.0 & 3.0 \\
\hline Maximum & 3.0 & 23.5 & 17.5 & 23.5 & 18.5 \\
\hline Number & 60 & 125 & 35 & 44 & 46 \\
\hline
\end{tabular}

Kruskal-Wallis: $\mathrm{H}=144.6756 ; \mathrm{p} \sim 0^{*}$. Dunn: Control $<\mathrm{Al}$, Control $<\mathrm{ACL}$, Control $<\mathrm{ACLMM}$ Control < N-OPER

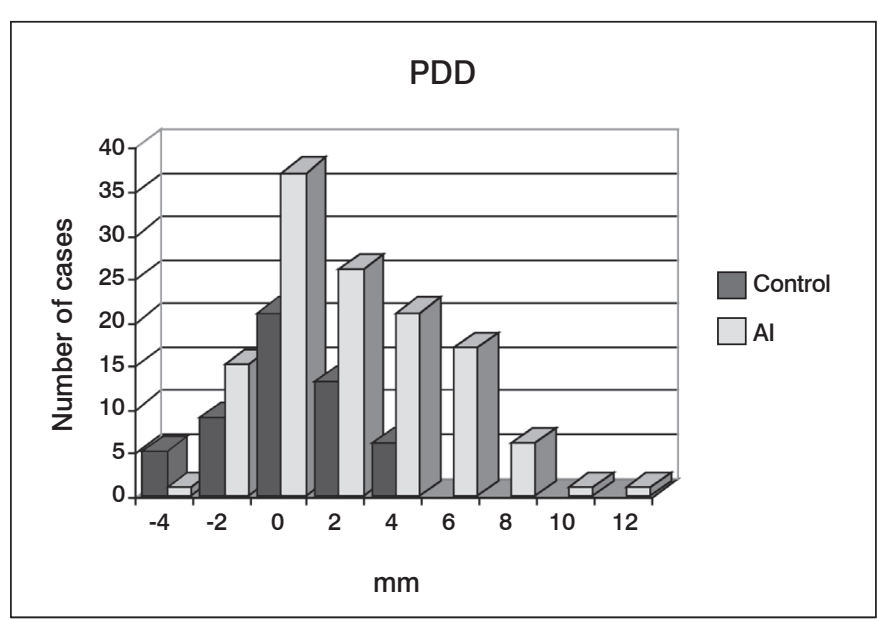

Figure 3. Histogram of the posterior displacement difference (PDD), in millimeters, of the control subjects (CONTROL) and of the patients with anterior knee instability (Al).

\section{DISCUSSION}

In our casuistic, the younger the patients that sustained $\mathrm{ACL}$ injuries, the more likely they were to be submitted to operative treatment, and the longer period of time between injury and treatment, more likely they were to present associated menisci injuries. ${ }^{14,15}$ 
Table 4. Descriptive statistic of the difference of posterior displacement between sides (PDD), in millimeters, of the Control and Al groups and of the subgroups ACL, ACLMM and N-OPER. Kruskal-Wallis comparison test and discrimination by the Comparison of Means test modified by Dunn $(\alpha=0.05)$

\begin{tabular}{c|c|c|c|c|c}
\hline & PDD $(\mathrm{mm})$ & & & & \\
\hline & Control & Al & ACL & ACLMM & N-OPER \\
\hline Mean & -0.22 & 1.92 & 2.81 & 2.11 & 1.04 \\
\hline Standard deviation & 1.65 & 2.99 & 3.04 & 2.59 & 3.13 \\
\hline Standard error of mean & 0.21 & 0.27 & 0.51 & 0.39 & 0.46 \\
\hline Minimum & -3.0 & -3.5 & -3.0 & -3.5 & -3.0 \\
\hline Maximum & 3.0 & 11.0 & 11.0 & 7.0 & 8.5 \\
\hline Number & 60 & 125 & 35 & 44 & 46 \\
\hline
\end{tabular}

Kruskal-Wallis: $\mathrm{H}=38.34$; $\mathrm{p} \sim 0^{*}$. Dunn: Control $<\mathrm{Al}$, Control $<\mathrm{ACL}$, Control $<\mathrm{ACLMM}$, Contro $<\mathrm{N}-\mathrm{OPER}$. N-OPER $<$ ACL. $\mathrm{P}=0.02^{*}$. N-OPER $<$ ACLMM. $\mathrm{P}=0.04^{*}$

Table 5. Mean values of the anterior (ADD) and posterior (PDD) displacement difference (injured-uninjured difference), in millimeters, in relation to time between injury and stressradiography (TIME), in years. Less than a year, between 1.1 and 2 years; between 2.1 and 3 years, between 3.1 and 4 years; and between 4.1 and 5 years.

\begin{tabular}{c|c|c}
\hline Time & ADD & PDD \\
\hline (Year) & $(\mathrm{mm})$ & $(\mathrm{mm})$ \\
\hline$<1$ & 9.47 & 1.57 \\
\hline $1.1-2.0$ & 10.65 & 1.83 \\
\hline $2.1-3.0$ & 9.17 & 2.12 \\
\hline $3.1-4.0$ & 10.67 & 2.78 \\
\hline $4.1-5.0$ & 10.28 & 2.6 \\
\hline
\end{tabular}

The stress radiography is a reliable method for the evaluation of the knee laxity. ${ }^{3,4,7-11,16}$ Both the magnitude and site of force application intervene in the absolute displacement. ${ }^{17}$ The sagittal displacement of the tibia increases with the applied force at a diminishing rate. Above $141 \mathrm{~N}$ practically no further increase of displacement occurs. ${ }^{18}$ The applied load can be constant ${ }^{4,7}$ to all individuals. We used $10 \%$ of the body weight of the patient. High loads can become uncomfortable, evoking muscle contraction of the thigh for protection of the knee. .,17,18 $^{-18}$

The paired right-left difference in the control subjects followed a Gaussian probability distribution ${ }^{19}$ in average, null. (Table 1) The maximum anterior (ADD) and posterior (PDD) displacement difference between sides of control subjects was $3 \mathrm{~mm} .{ }^{10,17}$ Gender, ${ }^{18,11}$ age, weight and height had no effect in right-left displacement differences.

The normal distribution of the anterior laxity in the Al group is shifted to the right (Figure 2, Table 2 and 3).3,4,7,10,13,19 Gender, weight, height, age of the patient at trauma or at exam, and associated menisci injuries did not affect the results of ADD (Table 2) as described in the literature. ${ }^{11} \mathrm{Al}$ group and subgroups have similar ADD all significantly different from the control group $(p \cong 0)$.
ADD increases with time between injury and exam $(p=0.02)$, i.e., the anterior instability increases with time. The increase in anterior laxity with time has been described ${ }^{10,13}$ as an increased structural damage to the $\mathrm{ACL}^{3}$ and as an overload process on the secondary restraints that finally loosens. ${ }^{1}$

In the progression of the anterior instability ostearthritic phenomena happens, such as narrowing of the intercondylar notch, flattening of the femoral condyles, osteophyte formation, narrowing of the joint-space, subchondral sclerosis and cyst formation. ${ }^{14}$ We believe there is also an anterior subluxation of the joint and that it precedes all other radiographic changes ${ }^{20}$ and it is not due to measurement technique errors. ${ }^{21}$ This displacement of the knee axis in the direction of the instability as described by Kärrholm et al., ${ }^{22}$ has been seen in orthostatic and unloaded radiographs ${ }^{8}$ and after ACL reconstructive surgery. ${ }^{16}$ Greater posterior displacement of ACL deficient knees submitted to posterior stress radiography, ${ }^{11}$ and no difference under posterior stress have been described ${ }^{4,7}$ and may be explained because of greater load, less time of instability, or associated lesions.

Nearly $1 / 3$ of the Al group presented PDD more than $3 \mathrm{~mm}$, i.e., an anterior subluxation when submitted to posterior stress. The injured knee positioned, in average, $1.9 \mathrm{~mm}$ anteriorly subluxated than the uninjured side. PDD control group was, in average, $-0.22 \mathrm{~mm},(p=0)$. Null PDD was the most frequent finding in all subjects; however, the Al group shows values up to $11 \mathrm{~mm}$. (Figure 3 and Table 4)

Al group and 3 subgroups presented anterior subluxation of the injured knee, all differing from the control group $(p \cong 0)$. (Table 4) Gender, age of the patients at injury or at stress radiography, weight, height and meniscal injuries had no influence on this anterior subluxation. But patients that chose not to be submitted to ACL reconstructive surgery had less anterior subluxation $(\mathrm{p}=0.04)$.

There is a clear increase of the PDD in the first four years of anterior instability, (Table 5) but no actual correlation with time of instability. There is direct relation, between the anterior subluxation (PDD) and the anterior translation (ADD). The ADD increases with time, and PDD increases with the ADD increase. From the anatomical point of view, either these patients had capsule and/or other ligament injuries acutely with the ACL injury, or they had a loosening of the secondary restraints leading to the anterior shift of the anatomic zero position of the injured knee. Posterior instability patients have posterior subluxation ${ }^{1,3,23}$ and, in our understanding, some of the patients with anterior instability, have anterior subluxation.

The lack of unloaded X-Rays to evaluate passive anterior shift of the knee axis is a limitation of the study. Magnetic resonance imaging confrontation would have been interesting.

\section{CONCLUSIONS}

The standardizing proposed is adequate to evaluate the sagittal displacement of the knee, without difference between sides in control subjects. ADD and PDD are not influenced by sex, age, weight, height, age at trauma or menisci lesions. The anterior instability increases with time. There is an anterior subluxation in patients with anterior instability. Patients that choose to treat conservatively, usually have less anterior subluxation. These two subluxated positions are directly related to each other. 


\section{REFERENCES}

1. Butler DL, Noyes FR, Grood ES. Ligamentous restraints to anterior-posterior drawer in the human knee. A biomechanical study. J Bone Joint Surg Am. 1980;62(2):259-70.

2. Rezende MU, Camanho GL, Hernandez AJ. Alteração da atividade esportiva nas instabilidades crônicas do joelho. Rev Bras Ortop. 1993;28(10):725-30.

3. Stäubli HU, Noesberger B, Jakob RP. Stressradiography of the knee. Cruciate ligament function studied in 138 patients. Acta Orthop Scand Suppl. 1992;249:1-27.

4. Lerat $\mathrm{JL}$, Moyen $\mathrm{BL}$, Cladière $\mathrm{F}$, Besse $\mathrm{JL}$, Abidi $\mathrm{H}$. Knee instability after injury to the anterior cruciate ligament. Quantification of the Lachman test. J Bone Joint Surg Br. 2000;82(1):42-7.

5. Böhler J. Röntgenologische Darstellung von Kreuzbandverletzungen. Chirurg. 1944;16:136-8.

6. Kennedy JC, Fowler PJ. Medial and anterior instability of the knee. An anatomical and clinical study using stress machines. J Bone Joint Surg Am. 1971;53(7):1257-70.

7. Lerat JL, Moyen B, Jenny JY, Perrier JP. A comparison of pre-operative evaluation of anterior knee laxity by dynamic X-rays and by the arthrometer KT 1000. Knee Surg Sports Traumatol Arthrosc. 1993;1(1):54-9.

8. Egund N, Fridén T, Hjarbaek J, Lindstrand A, Stockerup R. Radiographic assessment of sagittal knee instability in weight bearing. A study on anterior cruciate-deficient knees. Skeletal Radiol. 1993;22(3):177-81.

9. Hernandez AJ, Rezende UM, Camanho GL. "Lachman radiográfico": Uma proposta para a avaliação sagital da tíbia em relação ao fêmur. Rev Bras Ortop. 1992;27(5):709-15.

10. Kmen A, Bartalsky L, Pühringer A. [The radiological Lachman test: an extremely exact and predictive method for the assessment of recent and old injuries to the cruciate ligaments]. Unfallchirurg. 1991;94(8):390-4.

11. Torzilli PA, Greenberg RL, Hood RW, Pavlov H, Insall JN. Measurement of anterior-posterior motion of the knee in injured patients using a biomechanical stress technique. J Bone Joint Surg Am. 1984;66(9):1438-42.
12. Noyes FR, Grood ES, Torzilli PA. Current concepts review. The definitions of terms for motion and position of the knee and injuries of the ligaments. J Bone Joint Surg Am. 1989;71(3):465-72.

13. Pässler HH, März S. [The radiologic Lachman test--a simple and sure method for the detection of damage to the cruciate ligament]. Unfallchirurgie. 1986;12(6):295-300.

14. McDaniel WJ Jr, Dameron TB Jr. Untreated ruptures of the anterior cruciate ligament. A follow-up study. J Bone Joint Surg Am. 1980;62(5):696-705.

15. Rocha ID, Moraes TMS, Rezende MU, Pécora JR. Avaliação da evolução de lesões associadas à lesão do ligamento cruzado anterior. Acta Ortop Bras. 2007;15(2):105-8.

16. Almekinders LC, de Castro D. Fixed tibial subluxation after successfulanterior cruciate ligament reconstruction. Am J Sports Med. 2001;29(3):280-3.

17. Daniel DM, Malcom LL, Losse G, Stone ML, Sachs R, Burks R. Instrumented measurement of anterior laxity of the knee. J Bone Joint Surg Am. 1985;67(5):720-6.

18. Levén H. Determination of sagittal instability of the knee joint. Acta Radiol Diagn (Stockh). 1977;18(6):689-97.

19. Markolf KL, Amstutz HC. The clinical relevance of instrumented testing for $\mathrm{ACL}$ insufficiency. Experience with the UCLA clinical knee testing apparatus. Clin Orthop Relat Res .1987;(223):198-207.

20. Rezende MU, Camanho GL, Hernandez AJ. Lachman radiográfico" na avaliação dos joelhos cruzados deficientes. Rev Bras Ortop. 1993;28(5):251-7.

21. Rezende UM, Maia PT, Hernandez, AJ. Análise comparativa de diferentes métodos de avaliação do deslocamento sagital radiográfico do joelho. Rev Bras Ortop. 1995;30(5):293-7.

22. Kärrholm J, Selvik G, Elmqvist LG, Hansson LI, Jonsson H. Three- dimensional instability of the anterior cruciate deficient knee. J Bone Joint Surg Br. 1988;70(5):777-83.

23. Castle TH Jr, Noyes FR, Grood ES. Posterior tibial subluxation of the posterior cruciate-deficient knee. Clin Orthop Relat Res. 1992;(284):193-202. 